\title{
Rapid adhesive platelet count in whole blood
}

\author{
ROBERT D. EASTHAM
}

\author{
From the Department of Pathology, Frenchay Hospital, Bristol
}

SYNOPSIS A proportion of the platelets in whole blood become more adhesive when treated with adenosine diphosphate. After these platelets have adhered to the walls of a polystyrene container, E.D.T.A. is added and a count is made of the remaining platelets in the blood sample. By subtracting this latter count from the total whole blood platelet count a whole blood adhesive platelet count is obtained. For rapidity and accuracy, an electronic cell counter is used for each platelet count.

Platelets cannot become adhesive unless calcium ions and possibly magnesium ions are present (Bangham, Pethica, and Seaman, 1958; Brambel, 1961). In citrated blood platelets become adhesive in the presence of adenosine diphosphate (A.D.P.) when calcium ions are added (Born, 1963). Both E.D.T.A. and citrate in adequate concentration prevent platelet adhesiveness developing (Hellem, 1960). To combine ease of sampling and at the same time avoid reduction of platelet adhesiveness by such anticoagulants as citrate, oxalate, or E.D.T.A. heparin was used instead.

Perkins, Osborn, and Gerbode (1958) showed that when heparin was used as an anticoagulant some platelets lysed rapidly during the first five to 10 minutes after collection, having first aggregated into clumps. With an adequate concentration of heparin (more than 100 units $/ 1 \mathrm{ml}$. blood) the platelet count remained constant over a period of hours after the initial loss, and E.D.T.A. at a concentration of $4 \mathrm{mM}$. or more prevented the initial platelet loss which occurred with heparin alone (Perkins et al., 1958).

The platelets lysed by heparin were probably adhesive platelets, particularly since Hellem (1960) considers that the distinction between platelet aggregation and platelet adhesiveness to foreign surfaces is artificial. Also heparin does not affect platelet adhesiveness induced by added A.D.P. (Born and Cross, 1962).

\section{METHOD}

Blood collected into siliconed syringes is transferred into bottles containing dried E.D.TA. to give a final blood concentration of more than $4 \mathrm{mM}$. and into polystyrene bottles containing dried heparin to give a final blood concentration of more than 100 units $/ \mathrm{ml}$.

Received for publication 21 May 1963.
Both samples are mixed on a Matburn mixer at 30 r.p.m. until required. The heparinized sample can be left at this stage for at least two hours before the next stage.

A volume of $20 \mathrm{c.mm}$. of adenosine diphosphate solution in saline $(250 \mu \mathrm{g} . / \mathrm{ml}$. either freshly prepared or from a deep-frozen stock solution) is added to the heparinized blood sample. The solution of A.D.P. is at such a concentration that the final blood concentration is more than $0.6 \mu \mathrm{g} . / \mathrm{ml}$. (Born, 1963) and less than $6 \mu \mathrm{g} . / \mathrm{ml}$. The bottle is then returned to the mixer. After a further 30 minutes the heparinized A.D.P.-treated blood is transferred to an E.D.T.A. bottle, and again mixed. At this stage the two blood samples are stable for counting platelets for many hours, e.g., for 24 hours if kept at $4^{\circ} \mathrm{C}$.

Platelet counts are performed on each sample (Eastham, 1963) using a Coulter counter model $A$ and $70 \mu$ orifice tube. The adhesive platelet count $=$ total E.D.T.A. platelet count - heparinized, A.D.P.-treated sample platelet count.

\section{RESULTS}

After the addition of A.D.P. to the heparinized sample the platelet count reaches its lowest level at room temperature at 30 minutes, after which the platelet count slowly increases again towards its initial level (Fig. 1). The addition of E.D.T.A. to the heparinized sample at any stage of 'A.D.P. action' fixes the platelet count of that sample for at least 24 hours, even though A.D.P. activity may be either incomplete or waning.

Polystyrene containers consistently give higher adhesive platelet counts than do glass containers. This difference in counts was demonstrated using plain glass, siliconed glass, plain polystyrene, and siliconed polystyrene (Table I). It is possible that when maximum adhesiveness is developed platelets adhere one to another to form aggregates which spin out on centrifugation or they adhere to the vessel wall, or both. The possibility that platelets are 


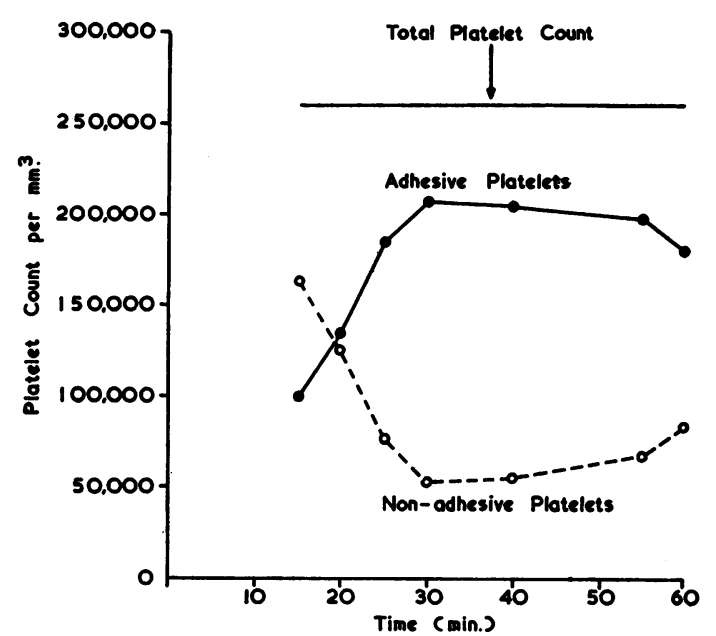

FIG. 1. Platelet counts after the addition of A.D.P.

lysed is unlikely, since as the action of A.D.P. wanes (or possibly adenosine monophosphate is generated) the platelet count slowly approaches normal again. At the height of the action of A.D.P., clumps of platelets can be picked off the vessel wall for microscopic examination and as activity wanes these platelet aggregates will disperse in saline.

The results obtained by this method may well be
TABLE I

WHOLE BLOOD PLATELET COUNT (E.D.T.A.) $=262,920$ per C.mm.

Container

Platelet Count (A.D.P. + Heparin per c.mm.)

Platelets Retained by

Container or Destroyed (per c.mm.)

Siliconed glass

Plain glass

Plain polystyrene

188,580

172,860

144,990

123,900

74,340 90,060

117,930

139,020

due to the action of added A.D.P. but it would $\stackrel{\omega}{\circ}$ appear that A.D.P. is the natural substance intimately concerned with platelet adhesiveness (Born, 1963; Gaarder, Jonsen, Laland, Hellem, and. Owren, 1961 ; O’Brien, 1962).

\section{REFERENCES}

Bangham, A. D., Pethica, B. A., and Seaman, G. V. F. (1958). Biochem J., 69, 12.

Born, G. V. R. (1963). Nature (Lond.), 194, 927.

- - , and Cross, M. J. (1962). J. Physiol. (Lond.), 166, 29-30P.

Brambel, C. E. (1961). In Blood Platelets, Henry Ford Hospital International Symposium, p. 123. Little, Brown, Boston, Mass.

Eastham, R. D. (1963). J. clin. Path., 16, 168.

Gaarder, A., Jonsen, J., Laland, S., Hellem, A., and Owren, P. A. (1961). Nature (Lond.), 192, 531.

Hellem, A. J. (1960). Scand. J. clin. Lab. Invest., 12, suppl., 51.

O'Brien, J. R. (1962). J. clin. Path., 15, 446.

Perkins, H. A., Osborn, J. J., and Gerbode, F. (1958). Amer. J. clin. Path., 30, 397. 